\title{
An unusual presentation of autonomic dysreflexia-autonomic dysreflexia due to pneumatic stockings
}

\author{
Ankita Madan, Saurabh Bhargava, Meenaxi Sharma, Karan Marwah ${ }^{1}$
}

\begin{abstract}
Autonomic dysreflexia is a potentially dangerous clinical emergency associated with spine injury at or above T6 level. Identification of triggering factor and its removal is a very important for the management of this condition. We hereby report a rare presentation of autonomic dysreflexia in a 57-year-old male, a case of $D_{9}-L_{1}$ arteriovenous malformation (AVM) with prolapsed intervertebral disc $L_{3}-L_{4}$ who underwent laminectomy from $D_{6}$ to $L_{4}$ level followed by excision of the AVM under general anaesthesia. He developed symptoms and signs suggestive of autonomic dysreflexia following application of intermittent compression pneumatic stockings which were reversed after the removal of the stimulus. Application of intermittent compression pneumatic stockings is an unusual cause of autonomic dysreflexia.
\end{abstract}

Key words: Autonomic dysreflexia, intermittent compression pneumatic stockings, spinal arteriovenous malformation, spinal surgery

\section{INTRODUCTION}

In high paraplegics and quadriplegics, Autonomic Dysreflexia is an important clinical emergency. Autonomic dysreflexia characterised by an abnormal autonomic response to a strong stimulus in a patient with a high thoracic spinal cord lesion. It is usually triggered by afferent stimuli below the level of injury. We hereby report a rare presentation of autonomic dysreflexia in a operated case of D9-L1 Arteriovenous Malformation (AVM) with prolapsed intervertebral disc (PIVD) L3-L4.

Departments of Anaesthesiology and Critical Care and ${ }^{1}$ Neurosurgery, NIMS Medical College and Hospital, Jaipur, Rajasthan, India

Address for correspondence:

Dr. Ankita Madan, Department of Anaesthesiology and Critical Care, NIMS University, Shobha Nagar, Jaipur - 303 121, Rajasthan, India.

E-mail: ankitamadan128@gmail.com

\begin{tabular}{|l|l|}
\hline \multicolumn{2}{|c|}{ Access this article online } \\
\hline Quick Response Code: & Website: \\
\hline & www.jnaccjournal.org \\
\cline { 2 - 2 } & \\
\hline
\end{tabular}

\section{CASE REPORT}

A 57-year-old male patient weighing $65 \mathrm{~kg}$, presented to our hospital with chief complaints of loss of sensation and pain in both lower limbs since $1 \frac{1 / 2}{2}$ years along with progressive difficulty in walking. The clinical examination revealed a motor power of $3 / 5$ in both lower limbs. After complete clinical examination and investigation, patient was diagnosed as a case of spinal arteriovenous malformation (AVM) at $\mathrm{D}_{9}-\mathrm{L}_{1}$ level along with $\mathrm{L}_{3}-\mathrm{L}_{4}$ prolapsed intervertebral disc (PIVD). The patient was scheduled for $\mathrm{D}_{6}-\mathrm{L}_{4}$ laminectomy and excision of the AVM under general anaesthesia. In the operating theatre, the routine monitoring (electrocardiography, pulse oximeter, non-invasive blood pressure [NIBP] and temperature) was started and patient was pre-oxygenated with $100 \%$ oxygen for $3 \mathrm{~min}$. General anaesthesia was induced with intravenous (IV) fentanyl $(2 \mathrm{mcg} / \mathrm{kg})$ and propofol $2 \mathrm{mg} / \mathrm{kg}$ and the muscle relaxation was achieved

This is an open access article distributed under the terms of the Creative Commons Attribution-NonCommercial-ShareAlike 3.0 License, which allows others to remix, tweak, and build upon the work non-commercially, as long as the author is credited and the new creations are licensed under the identical terms.

For reprints contact: reprints@medknow.com

How to cite this article: Madan A, Bhargava S, Sharma M, Marwah K. An unusual presentation of autonomic dysreflexia-autonomic dysreflexia due to pneumatic stockings. J Neuroanaesthesiol Crit Care 2017;4:178-80. 
using vecuronium $0.1 \mathrm{mg} / \mathrm{kg}$. The patient's trachea was intubated with $8.5 \mathrm{~mm}$ internal diameter cuffed endotracheal tube orally. Anaesthesia was maintained with sevoflurane in a mixture of oxygen $(40 \%)$ and nitrous oxide $(60 \%)$ along with an infusion of propofol, fentanyl and vecuronium. Surgery was done in the prone position and the intraoperative period was uneventful. Intraoperatively, no neuromonitoring was done for the patient.

At the end of surgery, the muscle relaxation was reversed and trachea was extubated uneventfully in the operation room, and the patient was shifted to intensive care unit (ICU) for further management. On admission to ICU, heart rate (HR) was 69 beats/min and NIBP was $141 / 91 \mathrm{~mm} \mathrm{Hg}$. In the post-operative period, pain was assessed using visual analogue scale. Pain was managed with diclofenac (aqueous) $75 \mathrm{mg}$ intravenous (i.v.) $\mathrm{BD}$ and paracetamol $1 \mathrm{gm}$ IV. every 6 hourly and the patient remained pain-free and comfortable. However, postoperatively, the patient was unable to move both his lower limbs (motor power was $0 / 5$ ). The case was discussed with neurosurgery team and spinal cord injury or cord oedema was suspected to be the most probable cause for immediate postoperative paraplegia. Since, the patient was fully conscious and oriented, any brain event was not expected. The fresh radiological investigations (magnetic resonance imaging spine) were advised but could not be obtained due to the refusal by patient's attendants. Since the patient was unable to move his lower limbs, intermittent pneumatic compression stockings were applied to both lower limbs as prophylaxis for deep vein thrombosis (DVT).

After $30 \mathrm{~min}$, the HR progressively decreased to 51 beats/min, along with rise in NIBP to 200/100 $\mathrm{mm} \mathrm{Hg}$ and he developed a severe headache. The patient did not complain of any pain at the site of surgery nor did he complain of any other discomfort. He was started on nitroglycerine (NTG) infusion @ $5 \mathrm{mcg} / \mathrm{min}$ which was gradually increased to approximately $35 \mathrm{mcg} / \mathrm{min}$ over a period of $1 \mathrm{~h}$. As the blood pressure (BP) remained uncontrolled, the patient was reassessed for the cause of hypertension. He was sedated using midazolam $1 \mathrm{mg}$ and fentanyl $100 \mathrm{mcg}$ IV slowly. However, patient's BP continued to remain high. Review of the patient's history did not reveal any new information. Since application of pneumatic stockings was the only intervention that was done in ICU before the BP increased, they were taken off.

The BP gradually decreased to within normal limits. Overnight, the BP remained between 118 and 136 $\mathrm{mm} \mathrm{Hg}$ systolic with an HR of $62-70$ beats/min. The NTG infusion was tapered gradually and later stopped.

Pneumatic stockings were reapplied in the morning and the same events repeated after application of pneumatic stockings. The BP again increased to $197 / 93 \mathrm{~mm} \mathrm{Hg}$ with a decrease in HR to 53-60 beats/min, for which he was again started on NTG infusion with progressively increasing dose. As there was no reduction in the BP, pneumatic stockings were removed which led to a gradual reduction of $\mathrm{BP}$ to $134 \mathrm{~mm} \mathrm{Hg}$ systolic with a HR of about 65 beats/min. The patient thereafter remained normotensive, and infusion of NTG was stopped. So to avoid using pneumatic stockings for DVT prophylaxis, pharmacological treatment with low molecular weight heparin (enoxaparin $40 \mathrm{mg}$ subcutaneous; once daily) was started $48 \mathrm{~h}$ after surgery, following the discussion with the surgical team. The patient was discharged on the $5^{\text {th }}$ postoperative day.

\section{DISCUSSION}

During spinal cord injury, there is disruption of neuronal pathways between the brain and spinal cord leading to lower resting arterial BP in the acute stage. However, in chronic spinal cord injury, at or above $\mathrm{T}_{6}$ level, there is an increase in arterial BP due to noxious stimuli below the level of the injury which is described as autonomic dysreflexia. ${ }^{[1,2]}$ Autonomic dysreflexia was described by Guttmann and Whitteridge in 1947, where he observed profound effects on cardiovascular activity due to distension of the viscera in a series of spinal patients. ${ }^{[3]}$ Autonomic dysreflexia is an emergency condition and the incidence ranges from $48 \%$ to $83 \%$ in patients with complete or incomplete injuries. ${ }^{[1,4,5]}$ It presents with transient hypertension, along with bradycardia, cardiac arrhythmias, piloerection, sweating, chills, nausea, severe headache and flushing above the level of lesion. ${ }^{[1,5,6]}$ It may be triggered by several factors such as any stimulus to lower urinary tract (urinary bladder distension, urinary tract infection, urethral distension, instrumentation, stones and testicular torsion), bowel distension due to faecal impaction, skin irritations, wounds, sores and ingrown toe-nails, pulmonary emboli, acute surgical abdomen, gastro-oesophageal reflux, skeletal fractures and intramuscular injections. ${ }^{[7]}$ In women, ovarian cysts, ${ }^{[8]}$ uterine contractions during menstruation or labour, ${ }^{[9]}$ and breastfeeding ${ }^{[10]}$ may also be the triggering factors. In most $(75 \%-85 \%)$ cases, urinary bladder distension is the triggering factor. ${ }^{[7]}$ There is individual variation in severity of cardiovascular dysfunction after spinal cord injury ${ }^{[11]}$ The severity of autonomic dysreflexia correlates with the completeness of spinal cord injury. Literature reveals that only $27 \%$ of incomplete quadriplegics present signs of autonomic dysreflexia in comparison with $91 \%$ of patients with complete quadriplegia. ${ }^{[12]} \mathrm{In}$ patients with complete spinal cord injury, there is also a higher risk of developing autonomic dysreflexia during initial hospitalisation as compared to 1-6 months after incomplete spinal cord injury patients. ${ }^{[4]}$ 
The patient described here was a case of dorso-lumbar AVM with L3-L4 PIVD who underwent D6-L4 laminectomy with excision of the AVM. He maintained normal HR and BP in the initial post-operative period. However, application of pneumatic stockings (triggering stimulus) caused decline in HR and rapid increase in BP to high levels. In injuries at or above T6, a noxious or non-noxious stimulus applied below the level of injury results in disorganised sympathetic response. ${ }^{[13]}$ The strong stimulus results in activation of the sympathetic system causing vasoconstriction below the level of injury. This reflex results in hypertension, due to splanchnic and peripheral vasoconstriction. The intact baroreceptors sense hypertension and send signals to the brain through cranial nerve IX and X. The descending inhibitory pathways are blocked by a discontinuous cord. This leads to activation of the parasympathetic system up to the level of the lesion causing bradycardia and vasodilation above the lesion and severe vasoconstriction below it, resulting in bradycardia with hypertension. [13] The paralysed veterans of America published the guidelines for treatment of autonomic dysreflexia. ${ }^{[14]}$ After diagnosing, autonomic dysreflexia, the first step of management is to make the patient sit in an upright position. The second step is look for any triggering factors. In case a cause cannot be identified, or BP is rapidly increasing then the medical treatment needs to be started. The antihypertensive drugs which have a rapid onset and short duration of action are generally used. In our case, the patient responded satisfactorily to the administration of NTG infusion and by removal of suspected stimulus (pneumatic stockings). Later, pharmacological treatment (low molecular weight heparin) was used as an alternative for pneumatic stockings for prophylaxis of DVT.

Thus, we conclude that autonomic dysreflexia is an important clinical entity in high thoracic spine injury patients. A high index of suspicion is necessary to establish the diagnosis and identify the cause. Triggering factor(s) should be removed immediately. Application of Pneumatic stockings is an uncommon cause of autonomic dysreflexia. To the best of our knowledge, this is the first case report describing pneumatic stocking as a trigger for autonomic dysreflexia, where the removal led to treatment of the condition.

\section{Financial support and sponsorship} Nil.

\section{Conflicts of interest}

There are no conflicts of interest.

\section{REFERENCES}

1. Karlsson AK. Autonomic dysreflexia. Spinal Cord 1999;37:383-91.

2. Teasell RW, Arnold JM, Krassioukov A, Delaney GA. Cardiovascular consequences of loss of supraspinal control of the sympathetic nervous system after spinal cord injury. Arch Phys Med Rehabil 2000;81:506-16.

3. Guttmann L, Whitteridge D. Effects of bladder distension on autonomic mechanisms after spinal cord injuries. Brain 1947;70(Pt 4):361-404.

4. Helkowski WM, Ditunno JF Jr., Boninger M. Autonomic dysreflexia: Incidence in persons with neurologically complete and incomplete tetraplegia. J Spinal Cord Med 2003;26:244-7.

5. Erickson RP. Autonomic hyperreflexia: Pathophysiology and medical management. Arch Phys Med Rehabil 1980;61:431-40.

6. Karlsson AK. Autonomic dysfunction in spinal cord injury: Clinical presentation of symptoms and signs. Prog Brain Res 2006; 152:1-8.

7. Lindan R, Joiner E, Freehafer AA, Hazel C. Incidence and clinical features of autonomic dysreflexia in patients with spinal cord injury. Paraplegia 1980;18:285-92.

8. Kiker JD, Woodside JR, Jelinek GE. Neurogenic pulmonary edema associated with autonomic dysreflexia. J Urol 1982;128:1038-9.

9. Burns AS, Jackson AB. Gynecologic and reproductive issues in women with spinal cord injury. Phys Med Rehabil Clin N Am 2001;12:183-99.

10. Devenport JK, Swenson JR. An unusual cause of autonomic dysreflexia. $60^{\text {th }}$ Annual Session of the American Congress of Rehabilitation Medicine and the $45^{\text {th }}$ annual Assembly of the American Academy of PM\&R. 6-11 November. California, USA: Balmaseda Publications; 1983.

11. Mathias CJ, Frankel HL. The cardiovascular system in tetraplegia and paraplegia. In: Frankel HL, editor. Handbook of clinical neurology. New York: Elsevier Science; 1992. p. 435-56.

12. Curt A, Nitsche B, Rodic B, Schurch B, Dietz V. Assessment of autonomic dysreflexia in patients with spinal cord injury. J Neurol Neurosurg Psychiatry 1997;62:473-7.

13. Petsas A, Drake J. Perioperative management for patients with a chronicspinal cord injury. BJA Educ 2015;15:123-30.

14. Consortium for Spinal Cord Medicine. Acute Management of Autonomic Dysreflexia: Individuals with Spinal Cord Injury Presenting to Health Care Facilities [Clinical Practice Guideline]. $2^{\text {nd }}$ ed. Washington: The Consortium, Paralyzed Veterans of America; 2001. 